\title{
RAZOAMENTOS SOBRE LETRAMENTO EM CONTEXTO DE AOLP
}

Reina Marisol Troca Pereira

(Universidade da Beira Interior - Portugal)

\section{RESUMO}

0 artigo apresenta-se como um ensaio sobre o ensino-aprendizagem, o uso e as implicações do Acordo Ortográfico da Língua Portuguesa (AOLP) de 1990, na literacia. Entre benefícios e problemáticas, cria-se um espaço de reflexão sócio-cultural, linguística e didáctica acerca da normalização de mudanças ortográficas. De uma amálgama de dificuldades de aprendentes e ensinantes resultam traços de justificado saudosismo, juntamente com mostras de entusiasmo, expectativa e resiliência na alfabetização funcional.

PALAVRAS-CHAVE: letramento; AOLP; ensino; aprendizagem.

"A linguagem é figura do entendimento [...]"

(OLIVEIRA: 7)

\section{Introdução}

No seguimento da vetusta afirmação em epígrafe, da primeira gramática de língua portuguesa, aprender a funcionar (cf. COLELLO 2003) com o instrumento da lingoagem abre rumo para uma panóplia de proficiências imediatas de alfabetização e também para práticas 
decorrentes do letramento (cf. LAZZAROTTO 2010; KLEIMAN 1995; CASTRO 1993) ${ }^{1}$, em particular no que concerne à competência de linguagem e à sua funcionalidade, incluindo capacidade de codificação de fonemas em grafemas; de descodificação e de uso de elementos prosódicos, acompanhados de gestos (BENAVENTE et al. 1996). Na realidade, mais pertinente do que elencar conhecimentos, importa saber utilizá-los e aplicá-los em contexto e (ou) situação comunicativa. Assim, em termos linguísticos, após a aprendizagem das letras, da grafia e da escrita, a literacia pressupõe capacidade de escrita, leitura, entendimento/compreensão e expressão.

Com este ensaio, propõem-se dois momentos de reflexão. Inicialmente, a título de contextualização do assunto em apreço, uma sinopse transversal respeitante a medidas de uniformização ortográfica nos espaços linguísticos do português. De seguida, apresentam-se algumas reflexões sumárias a propósito da aplicação das normas prescritas no Acordo Ortográfico da Língua Portuguesa (AOLP) de 1990 no processo de aquisição da língua portuguesa escrita, por aprendentes do espaço linguístico euro-afro-asiático-oceânico. Após considerações introdutórias de contextualização, expõem-se benefícios, resistências e problemáticas da recente reforma ortográfica, bem como consequências e implicações imediatas, no processo de ensino-aprendizagem, e duradouras, no conjunto de uma alfabetização funcional.

\section{De grafemas}

Porque o ser humano é secularmente reconhecido como um "animal político", no sentido etimológico (cf. Arist. Pol. 1453a), embora se constatem casos de isolamento e eremitismo, o seu carácter social remete para a necessidade de estabelecer actos de comunicação. Ora, em virtude da complexidade dos referentes semânticos, importa recorrer a signos, enquanto utilitários que permitem organizar conhecimentos e transmitir experiências, ainda que de modo parcial. Entre os diversos tipos de signos reconhecidos no âmbito das ciências semióticas ${ }^{2}$, destacam-se, entre outros, os ortográficos. Estes não se confundem com os signos linguísticos, que constituem objecto de estudo da Linguística enquanto ciência autónoma. De facto, a linguagem humana verbal vocal que pauta os interesses linguísticos caracteriza-se, desde logo, pelo binómio do bifacetamento dos signos linguísticos indicado por F. de Saussure ${ }^{3}$. Assim, um signo linguístico 
compõe-se de uma face de significado, correspondente a uma imagem mental de natureza abstracta, e de uma face de significante relativa à sua manifestação formal fónica, sendo a relação entre os elementos do binómio arbitrária.

Ora, como não se verifica uma correspondência unívoca entre o sistema gráfico e o sistema fonológico ${ }^{4}$ das línguas históricas naturais alfabéticas, gera-se a necessidade de recorrer a símbolos que, de forma convencional, permitem grafar usos linguísticos. 0 recurso aos sinais ortográficos, ainda que possibilite a conservação (parcial) de produções linguísticas, literárias (e ecfrásticas), não grava outros elementos significativos, designadamente gestos; elementos prosódicos ou supra-segmentais; aspectos relativos à concretização fónica indicadores de variação diatópica, diafásica, diastrática. Na sequência deste facto, A. Martinet (1960. Cf. 1989) salienta que, por um lado, o ser humano, antes de aprender a escrever, já utiliza uma língua para comunicar; por outro, indivíduos analfabetos/iletrados, embora não escrevam, expressam-se verbalmente; por outro ainda, há múltiplas línguas que não possuem código escrito. Ademais, os sinais ortográficos não são contemplados no postulado de Martinet relativo às unidades da dupla articulação da linguagem.

"Há milhares de anos que nos países civilizados se usam com frequência signos picturais ou gráficos correspondentes aos signos vocais da linguagem: é a chamada escrita. [...] Mas não esqueçamos que os signos da linguagem humana são prioritariamente vocais, que foram exclusivamente vocais durante centenas de milhares de anos e que ainda hoje a maioria dos homens sabe falar sem saber escrever nem ler. Nós aprendemos a falar antes de aprender a ler [...] o estudo da escrita constitui disciplina distinta da linguística." (MARTINET 1992:12-13)

Por conseguinte, o Homem, em termos gerais, nasce com uma capacidade (cf., com as devidas reservas, 'competence) de, quando estimulado no seio de uma comunidade linguística, concretizar essa potencialidade com a aprendizagem de uma língua, inicialmente por imitação, podendo desenvolver depois (institucionalmente) competências de entendimento e criação, bem como capacidades de reflexão metalinguística.

Assim, os primeiros estudos sobre as várias línguas revelam-se mormente prescritivos e normativos, visando as gramáticas $(\hat{o} Y \dot{Y} \div \mathrm{iç}$ ãñáìáôéêP. Cf., na Antiguidade, Panini; Dionísio Trácio; Apolónio 
Díscolo; Donato) estabelecer regras sobre utilizações correctas (usos orais e escritos) de uma língua.

Embora o português vernáculo tenha notícia medieval, a primeira gramática de língua portuguesa data apenas de 27 de Janeiro de 1536, pelo cunho de Fernão de Oliveira. A Grammatica da Lingoagem Portuguesa. Lisboa: Casa d'Germão Galharde, na sequência da necessidade de uniformizar com limites linguísticos uma realidade espácio-cultural mais abrangente e diversificada 5 . Em termos gerais, a escrita no espaço lusófono espelhava evidentes matrizes etimológicas greco-latinas ${ }^{6}$.

Embora a elaboração de gramáticas se alargasse, não obstou, todavia, à diversidade da língua portuguesa.

\section{Reformas Ortográficas: considerações diacrónicas}

No panorama gramatical lusofalante, destacam-se alguns estudos reformistas da grafologia oitocentista. Eis, pois, no cenário brasileiro, Frei Joaquim do Amor Divino Caneca, 1875. Corria o ano de 1877, quando João Barbosa Leão e um grupo de interessados em estabelecer a 'nova ortografia (sónica)' - Comissão do Porto - apresenta as suas propostas, sob princípios fonéticos, contudo sem lograr aceitação pela Academia de Ciências de Lisboa?

Em 1885, o escrito Bases da Ortografia Portuguesa, de A. R. Gonçalves Viana ${ }^{8}$ e Guilherme Augusto de Vasconcellos Abreu vem esclarecer sobre a "ortografia adoptada pelos editores técnicos da Enciclopédia da ciência, arte e literatura - Biblioteca de Portugal e Brasil", face à divergência de "ortografias das várias Redacções e estabelecimentos tipográficos". Destacam, neste sentido, "ortografias próprias" utilizadas por alguns escritores; a ortografia da Imprensa Nacional; e a da Imprensa da Universidade. Assim, torna-se necessária uma simplificação ${ }^{9}$ e uniformização ortográficas. Não obstante, o acolhimento da proposta não se fez sentir e o Presidente do Conselho, José Luciano de Castro Pereira Corte-Real, proibiu, em Diário do Governo, Portaria de 24 de Setembro de 1897, a introdução de tais medidas. Também com intuito unificador, considere-se, a 29 de Abril de 1898, a proposta do brasileiro Joaquim Francisco de Assis.

Até ao século XX, apesar do processamento normal da língua portuguesa enquanto organismo social vivo, contando-se alterações e variação, a ortografia não foi objecto de uniformização de usos nos 
diversos espaços falantes, em particular, por um acordo entre a Academia de Ciência de Lisboa (ACL) e a Academia Brasileira de Letras (ABL). Na ACL, a 13 de Junho de 1901, José Medeiros e Albuquerque apresenta uma proposta de nomeação de uma comissão de simplificação e uniformização ortográfica a ser aplicada também pela ABL. Dos trabalhos realizados pela Comissão constituída por José Medeiros, Albuquerque Silva Ramos e José Veríssimo não se contam resultados de maior. Em várias sessões, decorridas em 1906 e 1907, a ABL e a Comissão nomeada a 5 de Maio de 1906, composta por João Ribeiro, José Veríssimo e Silva Ramos procuram empreender simplificações de escrita, aproximando-a, sempre que possivel, da fala, erradicando da ortografia usual $^{10}$ marcas de uma grafia pseudo-etimológica (cf. AGUIAR 1984) ${ }^{11}$, nos projectos da reforma ortográficos votados e aprovados a 17 de Agosto $^{12}$.

No âmbito da primeira República Portuguesa, começa a preparar-se, em 1910, a primeira Reforma Ortográfica de 1911. A 17 de Dezembro de 1910, o funcionário da Imprensa Nacional José António Dias Coelho envia uma carta à administração, no sentido de se concertar uma uniformização ortográfica, face à diversidade de registos, recomendando-se as propostas presentes em Ortografia Nacional, de Gonçalves Viana. Consequentemente, por Portaria de 15 de Fevereiro de 1911, foi nomeada uma Comissão de Filólogos ${ }^{13}$ para atender ao assunto. Por Portaria de 12 de Setembro de 1911, publicada no Diário do Governo, foi ordenada a nova ortografia a ser implementada, até ao prazo máximo de 3 anos, em livros de ensino ${ }^{14}$. Não se verificaram, todavia, contactos com a ABL; porém, em 1911, registou-se o parecer favorável a um acordo interacadémico luso-brasileiro, por parte do académico brasileiro José Veríssimo.

Reacções às alterações ortográficas, na história da língua portuguesa, tidas como ecos de passadismo, incluíram, ainda assim, figuras de reconhecido valor, que, ultrapassando o alegado utilitarismo imediatista convergiam no entendimento da ortografia como um valor cultural e patriótico (cf. PEDROSA 2008; SOARES 1995). Eis, a título ilustrativo, Teixeira de Pascoaes (in A Águia), Alexandre de Fontes (A questão orthographica. Lisboa: Tip. da Coop. Militar, 1910: "Affligimo-nos extraordinariamente, quando pensamos que haveriamos de ser obrigados a escrever assim!"), Fernando Pessoa (cf. o heterónimo pessoano, Bernardo Soares. Livro do Desassossego), a propósito da reforma de 1911: 
0 Estado não tem direito a compellir-me, em materia extranha ao Estado, a escrever numa ortographia que repugno, como não tem direito a impôr-me uma religião que não acceito.

No Brasil a chamada reforma orthographica não foi aceite, nem ainda hoje, depois de assente em acordo entre o governo portuguez e brasileiro, é aceite. Quis-se impor uma coisa com que o Estado nada tem a um povo que a repugna.”(Dactiloescrito, BN)

Em 1915, a ABL apresenta a sua resolução no sentido da uniformização ortográfica; contudo, revoga-a em 1919. Retomados os esforços em 1924 (Vd. Laudelino Freire. Cf., já em 1920 e 1923, Júlio Dantas), apenas a 30 de Abril de 1931 resultaria o Acordo Ortográfico luso-brasileiro ${ }^{15}$, atribuindo Laudelino Freire, no Jornal do Comércio de 11-06-1931, a iniciativa ao Brasil. 0 sistema vigorante é publicado em Diário do Governo, em 25 de Maio de 1931, e oficializado pelo Ministro da Instrução Pública, dois dias depois, pela Portaria 7117. No Brasil, o procedimento segue pelo Decreto 20108, de 15 de Junho de 1931, a ser utilizado "nas repartições públicas e nos estabelecimentos de ensino”. De considerar, pese embora a vantagem reconhecida ao sistema ortográfico uniformizado, a necessidade de a simplificação respeitar determinados vectores, designadamente "a história, a etimologia e as tendências da língua”. Por conseguinte, ficam claros o desejo de acompanhar as evoluções da língua; a necessidade de uniformizar a escrita, mas não perdendo a consideração pela vertente diacrónica.

Em termos gerais, correspondia à norma de ortografia simplificada portuguesa de 1911/1920, com alterações pontuais requeridas pela $\mathrm{ABL}$ e reconhecidas pela ACL. Todavia, desentendimentos de índole nacionalista, reflectidos no Acordo, conduzem à ruptura, conforme expressa Leão. Tal levaria assim à determinação, pela Constituição da República dos Estados Unidos do Brasil, art. 26, de 16 de Julho de 1934, da adopção brasileira da ortografia que vigorava em 1891, por altura da primeira Constituição:

Ainda bem que o Acôrdo de 31 não era acõrdo, e que nos Entendimentos posteriores se resolveu que cada uma das duas nações fizesse, neste ponto grave, o que entendesse. (LEÃo 1934: 187)

Por determinação da ACL, decidiu-se a elaboração de um Vocabulário Ortográfico da Língua Portuguesa, desde meados da década de 30 até 1940, contando com a participação de especialistas como 
José Maria de Oliveira Simões, a quem se juntou, em 1938, Francisco da Luz Rebelo Gonçalves, destacando-se a reoficialização das consoantes etimológicas.

Segundo o presidente da ABL, Antônio Austregésilo, em 1939, a ortografia vigente no Brasil era a decretada em 23 de Fevereiro de 1938. Seguir-se-iam, a 29 de Janeiro de 1942, as Instruções para a Organização do Vocabulário Ortográfico da Língua Nacional (cf. Decreto-Lei no 5 186, de 12 de Janeiro de 1943); e, em Março de 1943, o Projeto do Vocabulário Ortográfico da Língua Nacional. RJ: Imprensa Nacional.

A Convenção Ortográfica Luso-Brasileira é assinada, em 1944, em Portugal, por António de Oliveira Salazar e pelo embaixador brasileiro João Neves da Fontoura e, no Brasil, por Getúlio Vargas. As Bases Analíticas do Acordo Ortográfico de 1945 são assinadas a 25 de Setembro e oficializadas em Portugal e nas colónias portuguesas, com aplicação imediata e, a partir de 1 de Janeiro de 1946, também em publicações. Constata-se a cedência da norma europeia em diversos aspectos, mas não quanto às ditas consoantes mudas. No Brasil, porém, apesar de oficializado o acordo (LL n ${ }^{\circ} 8286$ de 5 de Dezembro de 1945), a falta de consenso determinou o uso do acordo de 1943 (sistema ortográfico do PVOLP. Cf. lei n² 623, de 21 de Outubro de 1955).

Seguidamente, a 22 de Abril de 1971, resulta um breve e pouco significativo acordo entre a ACL e a ABL. Decretando a supressão maioritária de diacríticos, hífens e consoantes mudas, o Protocolo do Encontro de Unificação Ortográfica da Língua Portuguesa que contém as Bases analíticas da ortografia simplificada da língua portuguesa de 1945, renegociadas em 1975 e consolidadas em 1986, assinado a 12 de Maio de 1986, resultante do encontro de representantes da ACL, ABL e de seis países do CPLP, nunca recebeu aprovação.

A 14 de Dezembro de 1988, a Comissão Nacional da Língua Portuguesa (CNALP) proporciona a criação de um Anteprojecto de Bases da Ortografia Unificada da Língua Portuguesa, que viria a ser assinado a 16 de Dezembro de 1990 e ratificado ${ }^{16}$, em Portugal, em 4 de Junho 1991, estabelecendo-se a entrada em vigor a 1 de Janeiro de 1994. Contudo, o Brasil apenas ratificou o documento em 1995. 0 Primeiro Protocolo Modificativo ao Acordo Ortográfico da Língua Portuguesa seria ratificado por Portugal, a 28 de Janeiro de 2000 e o Segundo Protocolo Modificativo ao Acordo Ortográfico da Língua 
Portuguesa, em 2004 (Fortaleza). Em 2009, entra em vigor, em Portugal e no Brasil, o Acordo Ortográfico de 1990, tendo o texto sido ratificado por São Tomé e Príncipe, Cabo Verde, Timor-Leste e GuinéBissau. Moçambique ratificaria mais tarde, a 07 de Junho de 2012. A faltar, apenas Angola, que requer adequação/rectificação do Acordo.

\section{AOLP: Implicações para o letramento - recusa e resiliência}

Na realidade, em teoria e objectivo, a padronização ortográfica acordada em 1990 proporciona uma maior correspondência entre o sistema gráfico e o sistema fonológico (cf. MATEUS 2006; KOLINSKY; CARY; MORAIS 1987), ainda que os lexemas alterados representem uma percentagem diminuta do acervo ortográfico total (Em Portugal, c. $0,54 \%$, de um corpus de 110000 vocábulos), trata-se, não obstante, de um alargado vocabulário recorrentemente utilizado.

Ora, com as devidas reservas, é possível afirmar que o Acordo Ortográfico de 1990 facilita o processo de letramento de uma forma transversal e interestatal, no tocante à leitura e à escrita. Uma uniformização ortográfica faculta, outrossim, possibilidades de um maior dialogismo entre metodologias e práticas docentes a adoptar.

Todavia, verificam-se notórias resistências sociais e, em particular, académicas, que poderão confundir-se com dificuldades em aceitar a novidade e um saudosismo teimoso e conservador. Mas porque alterações da norma ortográfica não constituem algo inovador, por certo, os dilemas terão sido, mutatis mutandis, idênticos em todas as reformas e apenas absolutamente resolvidos aquando do passar de gerações. Há, contudo, que ponderar se o A0 de 1990 se apresenta como uma benesse injustamente mal recebida ou se existem de facto alguns assuntos que exigem ponderações mais profundas.

$\mathrm{Na}$ realidade, a população que conforma a comunidade linguística do português não se encontra devidamente elucidada, pese embora o manancial de sessões, colóquios, conferências (nacionais e internacionais) e os encontros recorrentes dos Ministros da Educação da Comunidade dos Países Língua Portuguesa (CPLP), do Conselho Científico do Instituto Internacional da Língua Portuguesa (IILP), do Instituto Internacional da Lusofonia entre outras entidades. Contudo, tais iniciativas não atingem as massas. E se o núcleo de discentes usufrui de esclarecimentos e práticas de leitura e escrita nas institui- 
ções de ensino, não se constata o desenvolvimento de acções de actualização de letramento para adultos (cf. TUIJNMAN 2000), incluindo professores, contribuindo-se assim para a instabilidade e a insegurança. Com efeito, deixa-se aos órgãos de comunicação social (televisivos - noticiários - e.g. RTP1, Bom Dia Portugal, "Bom Português"; legendagem; imprensa escrita), nem sempre devidamente esclarecidos, proporcionar aprendizagens 'naturais', pelo confronto directo frequente e repetido. Em termos de entendimento, pese embora alguma estranheza inicial, a comunicação fica assegurada, embora nem sempre esclarecida e ainda que por vezes confiada ao contexto a desambiguação (e.g. <para>). 0 mesmo, todavia, não acontece, necessariamente, com a criação escrita. Com efeito, ortografias anteriores não são retiradas do mercado livreiro e, perante dúvidas, verifica-se o recurso a correctores ortográficos computadorizados.

Em suma, o letramento constitui, no imediato, uma tarefa institucionalizada e dificultada, a começar por aspectos tão básicos como os nomes das letras ${ }^{17}$, e com reservas face a intervenções de familiares/sociedade envolvente e (ou) de fontes literárias disponíveis. Imperiosa será, pois, a recriação correctiva de novas representações ortográficas mentais do léxico (MARTINET. Cf. JAREMA; LIBBEN: 218).

\section{a Manifesto contra a maiusculização}

A permissibilidade de utilização de maiúsculas ou minúsculas e ainda a normalização de minúsculas em nomes de dias da semana, de meses, estações do ano, entre outros (Base XIX), sem justificação de maior, acarreta dificuldades nas primeiras aprendizagens, com consequências na classificação morfológica, designadamente com a redução de 'nomes próprios'.

\section{b Dupla Ortografia.}

Veja-se, pois, a falta de uma normalização absoluta de alterações, configurando um falacioso acordo de heterografias, com base na padronização de caóticas e arbitrárias desunificações ortográficas, conforme denota a Direcção Geral do Ensino Básico e Secundário, Parecer sobre o Acordo Ortográfico, 1991 (cf., no mesmo sentido, os Professores Catedráticos Vítor Aguiar e Silva - CNALP; Isabel Pires de Lima - FLUP; João Peres - FLUL, a título ilustrativo. Vd. EMILIANO 2008): "0 acordo recentemente assinado tem pontos que merecem 
séria contestação e é, frequentemente, uma simples consagração de desacordos."

A flexibilização admitida pela introdução da dupla grafia oficial, ainda que respeitadora de divergências fonéticas, acarreta problemas no letramento. Desde logo, a correcção de textos (cf. ortografia: @ñèüò- ãñüöù, 'escrever direito') complica-se e multiplica-se (e.g. <confeccionamos>, <confecionamos>, <confeccionámos>, $<$ confecionámos $>$ ), para docentes e discentes, com a apreensão de possibilidades, a exigência de uniformização do discurso escrito e a necessidade de cada escritor reflectir, na ortografia seguida, conformidade com a sua concretização fónica/prolação. Claro está que a situação alarga o panorama de aprendizagens e correcções, de modo a admitirem-se vários usos. Mas deverá o docente auscultar cada um dos seus alunos? E estes irão reproduzir os ensinamentos segundo a verbalização de cada docente, ou acumularão todas as possibilidades teóricas? E quando apenas o registo escrito está presente - haverá como decidir se a escolha tomada pelo escrevente é a mais adequada? Já agora, como lidar com as alterações ao longo da vida - poderá (e deverá) o mesmo escritor deixar na grafia empregue traços biográficos (e.g. (e)migração; comunidade em que se insere)?

\section{c Acentuação gráfica.}

0 critério fonético não explica, porém, obrigatoriamente, a erradicação de acentos agudos, que marcavam diferenças morfológicas, como < cantamos $>\sim<$ cantámos $>$ ou $<$ fábrica $>\sim<$ fabrica $>$ (Base IX, $4^{\circ}$, de carácter facultativo). É que o sistema fonológico do Português do Brasil é mais reduzido, o que justifica a medida, mas não a abolição do diacrítico. Contudo, na vertente europeia, a anulação da oposição /a/ / á/, favorecendo timbres mais abertos, constitui uma característica de uma variedade diatópica. Outrossim, a acentuação gráfica é facultativa em casos como < demos $>\sim<$ dêmos $>$ (Base IX, 8. ${ }^{\circ}, \mathrm{b}$ ). Mais ainda, no caso de $<$ para $>$, acumula-se a preposição com a forma verbal (Base IX, 6. ${ }^{\circ}$ ). Todavia, a razão invocada não tem aplicação em <pôr > < por> ou <pode> <pôde>, precisamente para evitar a ambiguidade (Base VIII, 3. ${ }^{\circ}$ e Base IX, 6. ${ }^{\circ}$, a, respectivamente). De realçar também a abolição do diacrítico em casos como <heroico $>$, aproximando o som vocálico da realização em <oito $>$. 
Existe, ainda assim, a possibilidade de dupla acentuação gráfica (c. 1,27\%), ente diacríticos agudos e circunflexos, numa lógica de entendimento de 'agradar a gregos e a troianos', e.g. <génio / gênio>.

\section{d. Consoantes não articuladas.}

No referente ao controverso tópico das letras consoantes erroneamente apelidadas 'mudas', isto é, às quais não corresponde nenhuma verbalização ('não articuladas' ou 'inorgânicas'), ainda que discutível e longe da consensualidade, é no Anexo II c do documento que se discorre a imperiosidade da alteração.

A necessidade de uniformização era já notória em 1885 (“convicção de que não haverá unificação ortográfica da língua portuguesa se tal disparidade não for resolvida”), contemplando-se então alguma permissividade, no tocante a influências relativamente aos fonemas /i/, /u/. Assim, admitem-se edito = edicto; corruto = corrupto; corrução = corrupção. De facto, certas consoantes sem concretização fónica já haviam sido retiradas, como em < dicionário $>$.

Ainda assim, em termos históricos, Vianna e Abreu. Bases da Ortografia Portuguesa. Lisboa: Imprensa Nacional, 1885 (campo II. Valor histórico dos fonemas ainda proferidos e dos que já não se proferem; influência destes sôbre a modulação da vogal precedente: 10-11), no capítulo respeitante à Adopção de Letras Consoantes, 4.2.e), apresenta a manutenção etimológica de grafemas, sempre que influentes para os sons vocálicos anteriores: "Conservamos todo o sinal gráfico de fonema histórico, hoje nulo, cuja influência na vogal precedente é persistente: acção, actor, predilecção, redacção, respectivo, trajectória, baptismo, concepção; e ainda quando é facultativa a pronunciação, como em carácter."

Na realidade, a manutenção de grafemas etimológicos sem aparente pertinência linguística pode explicar determinadas verbalizações no Português Europeu (PE). De facto, o sistema vocálico em posição átona, no PE, tende para o fechamento do grau de abertura. Explicam-se excepções a este preceito com razões de índole histórica/ etimológica e (ou) analógica (e.g. <optimizar>, face a <óptimo>). Assim, director, respectivo, acção. 0 mesmo não se aplica ao Português do Brasil, cujo sistema fonológico é mais reduzido.

Ademais, invocar a pronúncia como fundamento para a alteração ortográfica constitui, no mínimo, um argumento pseudocientífico. 
$\mathrm{Na}$ realidade, por um lado, as línguas tendem a evoluir numa lógica reducionista, o que, dando prosseguimento sem limites a esse princípio, prenuncia um acervo fonológico de grunhidos e a oficialização de ortografias telegráficas como as já empregues em comunicações via digital (e.g. computador; telemóvel). Por outro lado, a substituição da erudição, como se uma malvadez nefanda se tratasse, por uma ditadura fonética ${ }^{18}$, com fraco controlo, podendo resvalar para uma anarquia inconsequente e dando azo até a posições anti-ortográficas, acarreta diversos e perigosos dissabores, com repercussões indeléveis, como os seguintes:

. favorecimento de um padrão de verbalização da língua, em detrimento dos demais. Porém, a pronúncia enquanto manifestação fónica traduz-se num factor de identidade, transmitindo, para além dos conteúdos semânticos do discurso, elementos relativos ao emissor, em termos particulares e enquanto elemento integrado na comunidade linguística, atendendo outrossim, ao contexto e (ou) situação comunicativa. Ademais, em alguns casos, a supressão do grafemas sem articulação é facultativa, face a pronúncia culta, o que resulta numa discriminação dos utilizadores de uma língua, desde logo relativamente a lusofonias além de Portugal e Brasil, com as suas variações. Noutros casos, porém, a conservação é obrigatória (e.g. PE: $<$ facto $>$; PB: <percepção $>$ (PE: <perceção $>$ ).

. retrocesso à estratégia fonológica inicial de literacia, num manifesto laxismo disfarçado de cientificidade, fazendo crer na possibilidade de ligar univocamente dois sistemas distintos, viz. o gráfico e o fonológico, tornando o primeiro dependente do segundo.

. multiplicação de homónimos, apelando ao contexto para distinguir, e a explicações etimológicas, juntamente com ditames históricos extralinguísticos, para justificar.

. dificuldade de exploração de análises etimológicas, impedindo e (ou) obstaculizando apreensões semânticas em análises literárias e criando, no inverso, espaço para se desenvolverem falsos paralelismos, pseudo-analogias e etimologias inexistentes (cf. <inspetor $>$ ).

. falta de uniformização (cf. alargamento de heterografias) e pseudocientificidade.

. confusão na aprendizagem de vocábulos de uma mesma família linguística. 
- quiçá tentativas emulativas da prolação brasileira.

. falta de coesão e coerência na aplicação do princípio fonético a toda a língua.

. Ortografia: bode expiatório da iliteracia?

No Anexo II. 4.2.c do A0 invocam-se dificuldades de aprendizagem e memorização ortográficas por crianças de 6-7 anos (cf. CASTRO, S.; VICENTE, S.; MORAIS, J.; KOLINSKY, R.; CLUYTENS, M. 1995; BYRNE 1997) ${ }^{19}$ para eliminar grafemas sem articulação. Seria a ortografia a causa da iliteracia/iletramento? Constituirá o A0 o salvador da cultura?

A preocupação parece ter ganhado quiçá demasiada relevância, caso se considere que a aprendizagem de qualquer norma ortográfica requer esforço. Desde logo, trata-se de contactar com um código de símbolos, com uma ligação arbitrária, nem sempre unilateral aos sons emitidos. Ambas as realidades (de natureza escrita e sonora) não deixam nunca de ser distintas. Mais ainda, nesse processo de aprendizagem sincrónica parece nunca existir espaço para possíveis esclarecimentos etimológicos. Com efeito, a alfabetização e o letramento não se aplicam somente às faixas etárias indicadas no referido ponto do Anexo, nem tampouco o ensino da ortografia se restringe à exposição de um conjunto de normas a decorar, devendo, dentro do possível e quando adequado, as aprendizagens realizar-se de forma reflexiva e clarificada. Há, pois, que explorar razões históricas/etimológicas; considerar as memórias visuais criadas; bem como processos de percepção da fala e reflexos no falar, com influências na aç̧ão e na cognição.

E mesmo em termos sincrónicos há dificuldade em explicar variações de pronúncia, escrita (e.g. PE: <receção $>$ / PB: <recepção>) e semântica nos diversos espaços, para além de étimos relacionados, mantendo-se a articulação, e.g., em <egípcio>, mas abolindo-se a consoante em $<$ Egito $>$.

. A0: o arauto da morte ortográfica?

Nesta lógica simplificativa do A0 poderá estranhar-se a manutenção de certos símbolos gráficos que, isolados, não detêm valor, nem mesmo uma tradição histórica, como é o caso da aspiração, inexistente, à época, na matriz latina. 0 caso é real e justifica algumas das dificuldades sentidas no letramento. Conserva-se, porém, tanto nas normas ortográficas portuguesa como brasileira, uma reminiscência histórica, sem pertinência linguística - e.g. <homem>, <huma- 
no $>$, face ao desaparecimento de $<\mathrm{h}>$ em formas derivadas ${ }^{20}$, como $<$ desumano $>$.

A título ilustrativo, outras letras há sem realização fónica, em certos contextos, como $<\mathrm{u}>\mathrm{em}<$ guerra $>$, mas já com articulação em $<$ guarnecido $>$ - a falta que fará o uso do trema no PB!

E o que afirmar de realizações distintas do grafema $<u>$, quando verbalizado em final de sílaba como semivogal velar, no PB, e como lateral alveolar velarizada, no PE - o que justifica alargar a ponderação sobre a uniformidade ortográfica pretendida, mediante um critério essencialmente fonológico, à utilização de grafemas $(<\mathrm{m}$, $\mathrm{n}>$ ), que poderiam substituir-se por diacríticos $(<\sim>$ para grafar nasalidade. Cf. $<$ lã $>$, perante $<\operatorname{sim}>$ ). Ou porque manter dígrafos e grafias diversas correspondentes ao mesmo som, como o fricativo pré-dorso-palatal surdo: $<$ chama $>,<$ xadrez $>$; ou a confusão de sonoridades a partir de um mesmo grafema: $\langle\mathrm{x}>$ : $<\operatorname{sintaxe}>$, $<$ exame $>$, $<$ enxame $>$, <axioma $>$ ? E afirmar casos vocabulares de outras línguas românicas (cf. Anexo II 4.2: Ptg.: <objeto>; Cast. <objeto>; Fr. <objet>), face aos étimos latinos não apresenta pertinência, pois os factos de uma língua apenas e só a ela lhe pertencem.

\section{Inconstâncias e lncoerências.}

Ora, após múltiplas discussões, sem prover ao desidério inicial de simplificar o uso de grafemas, só na sequência do Acordo ${ }^{21}$ de 1990 se adoptará nova grafia nos Estados que ratificaram o documento, sem que se fizesse sentir uma evolução natural com base nessa suposta necessidade. Destaca-se, em particular, a aproximação entre Portugal e Brasil, face a outros Estados da norma euro-afro-asiáticooceânica, tradicionalmente, por questões históricas, próximos da norma escrita europeia. Ganha, por conseguinte, a adopção de um entendimento ortográfico luso-brasileiro. A convergência ortográfica responde mormente a uniformizações de textos oficiais e burocráticos, bem como a aberturas económicas de mercado, mais do que a pseudoproblemáticas de entendimento, a julgar por outros casos linguísticos que não propõem alterações desta índole. Assim se contam exemplos das línguas francesa e inglesa, utilizados em diferentes espaços geográficos (e.g. color - am. / colour- brit.; center/centre; analyze/analise; travelling/travelling; pediatic/paediatic; offense/ offence; analog/analogue). 
Compete outrossim reflectir, entre inconstâncias e incoerências do A0, a propósito da erradicação de alguns hífenes e a manutenção de outros, em situações aparentemente análogas, sem explicação de valor, além da consagração pelo uso (cf. Base XV, 6. ${ }^{\circ}$. e.g. <cor-derosa $>$, mas $<$ cor de laranja $>)^{22}$. Desfaz-se, pois, a certificação de unidades sintemáticas e dificultam-se aprendizagens e usos correctos e conscientes.

\section{Nota Conclusiva}

Não obstante imprecisões técnico-científicas ${ }^{1}$ do texto final do Acordo Ortográfico de 1990, a sua facultatividade e falta de congruência, em múltiplas ocasiões, traduz-se numa afectação considerável da disortografia não unificada imposta, com notórias implicações no processo de literacia de crianças e adultos. 0 Novo Acordo Ortográfico, longe de constituir um instrumento facilitador da literacia, reflecte insegurança. Embora possa argumentar-se que o texto do Acordo pode ser revisto e rectificado, de modo a não impedir a unificação da ortografia da língua portuguesa, a demora das alterações ${ }^{2}$ (quiçá) a apresentar constitui um ónus constante para as aprendizagens.

E ademais, caso o desejo mascarado seja o da unificação da língua portuguesa, as alterações ortográficas, ainda que reconhecido o mérito da criação de símbolos ortográficos pela Humanidade (LOGAN 1986), aplicam-se somente na escrita morfológica, mas sem implicações em termos de verbalização (cf. 'pronúncia') ${ }^{33}$ Cf. OLIVEIRA, 1975 [1536], p. 52:

“(...) nisto consiste o saber ler, e mais que saber ler. E é verdade que, se não tivermos certa lei no pronunciar das letras, não pode haver certeza de preceitos nem arte na língua, e cada dia acharemos nela mudança, não somente no som da melodia, mas também nos significados das vozes, porque só mudar uma letra, um acento ou som, e mudar uma de vogal grande ou pequena ou de pequena a grande, e assim também de uma consoante dobrada em singela ou, ao contrário, de singela dobrada, faz ou desfaz muito no significado da língua." 
The article is an essay about the teaching - learning process, the use and the implications of the Portuguese Language Orthographic Agreement (PLOA) of 1990 in literacy. Between benefits and problems, is created a space for socio-cultural, linguistic and didactic reflection about the standardization of spelling changes. From an amalgam of difficulties for learners and teachers results some justified nostalgia, together with evidence of enthusiasm, hope and resiliency in functional literacy.

KEYWORDS: literacy; PLOA (AOLP); teaching; learning.

\section{REFERÊNCIAS}

AGUIAR, G. de. Ortografia portuguesa e etimologia. Estudos Leopoldenses 21, 1984, pp. 1-216.

ASSUNÇÃO, M. Origens e Ortografia da língua brasileira: 0 'Livro Branco' do acordo ortográfico luso-brasileiro. Rio de Janeiro: Livraria H. Antunes, 1933.

BALLY, C.; SECHEHAYE, A.; RIEDLINGER, A. (eds.). F. de Saussure. Cours de linguistique générale. Paris: Payot, 1916.

BENAVENTE, A. et al. (coord.) A literacia em Portugal. Resultados de uma pesquisa extensiva e monográfica. Lisboa: Fundação Calouste Gulbenkian, 1996.

BYRNE, B. The learnability of the alphabetic principle: children's initial hypotheses about how print represents spoken language. Applied Psycholinguistics, 17, 1997, pp. 401-426.

CASTRO, S. Alfabetização e percepção da fala. Porto: Instituto Nacional de Investigação Científica, 1993.

CASTRO, S.; VICENTE, S.; MORAIS, J.; KOLINSKY, R.; CLUYTENS, M. Segmental representation of Portuguese in 5- and 6- year olds: Evidence from dichotic listening. in Faria, I.; Freitas, J. (eds.), Studies on the acquisition of Portuguese. Proceedings of the First Lisbon Meeting on Child Language. Lisboa: Colibri, 1995, pp. 1-16.

COLELLO, S.; SILVA, N. Letramento: do processo de exclusão social aos 
vícios da prática pedagógica. in VIDETUR, 21, 2003, pp. 21 - 34.

EMILIANO, A. O Fim da Ortografia. Lisboa: Guimarães Editores, 2008.

GONCALVES, M. As idéias ortográficas em Portugal: de Madureira Feijó a Gonçalves Viana (1734-1911). Lisboa: Fundacao Calouste Gulbenkian/ Fundacao para a Ciencia e a Tecnologia, 2003.

GOODMAN, Y. Developing writing in a literate society. Educational Horizons, 64(1), 1985, pp. 17-21.

G00DY, J. (ed.) Literacy in traditional societies. New York: Cambridge University Press, 1968.

HOUAISS, A. A nova ortografia da língua portuguesa. São Paulo: Ática, 1991.

JAREMA, G.; LIBBEN, G. The Mental Lexicon: Core Perspectives. Boston: BRILL, 2007.

KEMMLER, R. 0 destino de um projeto linguístico da Republica Portuguesa no mundo lusófono: a questão da ortografia simplificada desde 1910 até 2010, Cadernos Eborenses: Revista Internacional de Tradução, linguística e Literatura, 2, 2011, pp. 9-45.

KEMMLER, R. Para uma História da Ortografia Portuguesa: o texto metaortográfico e a sua periodização do século XVI até ã reforma ortográfica de 1911. Lusorama 47-48, 2001, pp. 128-319.

KLEIMAN, A. (org.) Os significados do letramento: uma nova perspectiva sobre a prática social da escrita. Campinas: Mercado das Letras, 1995.

KOLINSKY, R.; CARY, L.; MORAIS, J. Awareness of words as phonological entities: the role of literacy. Applied Psycholinguistics, 8, 1987, pp. 223-232. LAZZAROTTO , E. Alfabetização e Letramento. Rio Grande do Sul: Três Cachoeiras, 2010.

LEA0, J. Coleção de estudos e documentos a favor da reforma da ortografia em sentido sônico. [s/l], 1878.

LEITE, S. (org.) Alfabetização e letramento - contribuições para as práticas pedagógicas. Campinas: Komedi/Arte Escrita, 2001.

LOGAN, R. The Alphabet Effect: the impact of the phonetic alphabet on the development of western civilization. New York: St. Martin's Press, 1986.

MARCUSCHI, L. Da fala a escrita: atividades de retextualização. São Paulo: Cortez, 2007.

MARTINET, A. Éléments de linguistique générale, Paris: Armand Colin, 1960 (trad. Port. - Lisboa: Livraria Sá da Costa Editora, 1992).

MARTINET, A. Function et dynamique des langues. Paris: Armand Colin, 1989. 
MATEUS, M. Sobre a natureza fonológica da ortografia portuguesa. Lisboa: FLUL, 2006.

PEDROSA, J. Literacia, condição de cidadania. in AAVV. Literacia em Português. Lisboa: Fundação Calouste Gulbenkian, 2008, pp. 113-117.

RIBEIRO, V. (org.) Letramento no Brasil. São Paulo: Global, 2003.

SÃ, F. de. A Língua Portugueza: (Difficuldades e duvidas), Com uma critica por Candido de Figueiredo, edição de Fran Paxeco, Maranhão [S. Luís]: Imprensa Oficial, 1915.

SCRIBNER, S.; COLE, M. The psychology of literacy. Cambridge: Harvard University Press, 1981.

SILVA, M. (org.). Ortografia da língua portuguesa: história, discurso e representações. Sao Paulo: Contexto, 2009.

SOARES, M. Língua escrita, sociedade e cultura: relações, dimensões e perspectivas, Revista Brasileira de Educação, n. 0, 1995, pp. 5 - 16.

STREET, B. Literacy in theory and Practice. Cambridge, University Press, 1984.

TEALE, W. Libraries promote early literacy learning: ideas from current research and early childhood programs. Journal of Youth Services in Libraries. 12(3), 1999, pp. 9-16.

TFOUNI, L. Letramento e alfabetização. São Paulo, Cortez,1995.

TUIJNMAN, A. (ed.) et al. Literacy in the Information Age. Final Report of the International Adult Literacy Survey. Paris: OECD/Statistics Canada, 2000. TUIJNMAN, A. et al. Literacy, Economy and Society: Results of the First International Adult Literacy Survey. Paris: OECD/Statistics Canada, 1995.

NOTAS

${ }^{1}$ Cf. as terminologias de literacia (PE) e letramento (PB).

${ }^{2}$ Cf. no âmbito das ciências gerais dos signos (óçiåöií), a tradição europeia, marcada pelos estudos semiológicos saussurianos; e os estudos anglosaxónicos, realçando-se os estudos semióticos de Charles Sanders Peirce.

${ }^{3} \mathrm{Vd}$. a obra de conteúdo expresso por Saussure, ainda que de composição e publicação póstuma. Cf. BALLY; SECHEHAYE; RIEDLINGER 1916.

${ }^{4}$ Cf. o surgimento de Alfabetos Fonéticos, no sentido de proporcionar a 
correspondência unívoca de um símbolo a um tipo de som. Cf. AFI/IPA (Alfabeto Fonético Internacional/International Phonetic Alphabet), criado na sequência da International Phonetic Association (Dhi Fonètik Tîcerz' Asóciécon), Paris, 1886. Com grande pertinência para a língua portuguesa, é também de salientar o Alfabeto Fonético de Paiva Boléo.

5 São diversas as propostas ortográficas da língua portuguesa, desde as primeiras gramáticas seiscentistas, de Fernão de Oliveira e João de Barros, Grammatica da lingua portu-guesa, 1540, tendo em consideração outras gramáticas, como as de Nebrija, Grammatica Antonii Nebrissensis 1492 e Trissino, Epistola de le lettere nuwvamente aggiunte ne la língua italiana, Roma, 1524. Cf., a respeito da língua portuguesa, GONCALVES 2003; KEMMLER 2001; KEMMLER 2011.

${ }^{6}$ Cf., sobre a ortografia da língua portuguesa, reflexões seiscentistas, como Amaro de Roboredo. Regras da Orthographia Portugueza, 1615; Álvaro de Vera. Orthographia ou modo para escrever certo na língua portugueza. Com um tractado de memoria artificial: outro da muita similhança que tem a lingua portugueza com a latina, 1631 (cf. 1638); Bento Pereira, Regras geraes, breves e comprehensivas da melhor orthographia, com que podem evitar erros no escrever da língua latina e portugueza, para se ajuntar á Prosódia, 1666; João Franco Barreto, Orthographia da língua Portugueza e Notas á de Duarte de Leão, 1670; João Franco Barreto, Orthographia da língua Portugueza, offerecida ao senhor Francisco de Mello, 1671, entre diversas outras.

${ }^{7}$ Cf., sequentemente, José Ventura Boscoli. Grammatica Portugueza: Estudo Racionado segundo os princípios Hodiernos da sciencia da linguagem, 1894. ${ }^{8}$ Cf. também, do mesmo autor, Ortografia Nacional: simplificação e uniformização sistemática das ortografias portuguesas, 1904; Vocabulário Ortográfico e Ortoépico da Língua Portuguesa, 1909.

9 Simplificações ortográficas tendo em consideração questões fonéticas podem acarretar efeitos para a ortografia, conforme refere o apontamento do filólogo Filipe Franco de Sá (1906, ed. 1915), face a Gonçalves Viana, referindo-se à pronúncia brasileira. Reconhecem-se já diferenças relativamente ao PE e equaciona-se a sua importância para a norma ortográfica: "Mas, quanto á qualidade do som, a pronuncia, em Portugal é differente da nossa, como adiante diremos. Compete á Academia Brasileira de Letras, quando se julgar para isso com autoridade bastante, decidir se convem acceitar a accentuação graphica dos portuguezes, procurando a gente culta conformar com ella a pronuncia; ou continuarmos a não pôr accento senão nos casos em que hoje commummente se põe; ou, finalmente adoptarmos diferente accentuação, conforme á nossa pronuncia. 0 melhor fôra, a ser possivel, que a nossa 
Academia chegasse a um accordo com a de Lisboa sobre a orthographia para que se não escreva a língua diversamente, na Europa e na America.” (SÃ 1915: 71).

${ }^{10}$ Cf. Presidente do Conselho, Ernesto Rodolfo Hintze Ribeiro, em Diário do Governo, Portaria de 1 de Fevereiro de 1901, a propósito do conceito de orthographia usual, como a que é utilizada em dicionários contemporâneos de referência e pelos "principaes auctores classicos modernos". Em termos sucintos, conciliava as versões etimológica e fonética da ortografia.

${ }^{11} \mathrm{Vd}$. por vezes excessos ditados pela defesa da preservação extrema de bases etimológicas, quase pautando pela transliteração de vocábulos latinos. Cf. José Feliciano de Castilho Barreto e Noronha.

${ }^{12}$ Sobre a iniciativa de estabelecer um acordo ortográfico luso-brasileiro e a influência da norma portuguesa, cf. a afirmação de MEDEIROS e ALBUQUERQUE, J. Vocabulário Brasileiro da Ortografia Oficial. São Paulo; Rio de Janeiro; Belo Horizonte: Livraria Francisco Alves, 1933, p. 7: "Foi em 1907 que a Academia Brasileira se ocupou pela primeira vez com a ortografia. Partiu de mim a iniciativa para esse ato." Similarmente, AGUIAR (1984: 65): "Observando bem o texto desta reforma [de 1907], notamos imediatamente a influéncia do grande mestre português, Gonçalves Viana, em Ortografia Nacional, de 1904. Seu apelo teve eco primeiro aqui. Lá, só diante de nossa reforma. Breve, começariam os acórdãos entre as duas nações.”

${ }^{13}$ Considerem-se Carolina Michaelis de Vasconcelos; Aniceto dos Reis Gonçalves Viana; António Cãndido de Figueiredo; Francisco Adolfo Coelho e José Leite de Vasconcelos, a quem se juntaram seis vogais, a partir de 15 de Março de 1911: Augusto Epifãnio da Silva Dias; Manuel Borges Grainha; António José Gonçalves Guimarães; Júlio Moreira; José Joaquim Nunes e António Garcia Ribeiro de Vasconcelos.

${ }^{14}$ Cf. a publicação também de Formulário Ortográfico e um Prontuário Ortográfico. Vocabulário Ortográfico e Ortoépico da Língua Portuguesa de 1911. Em 1912, Gonçalves Viana publicou o Vocabulário Ortográfico e Remissivo da Lingua Portuguesa. Vd. Cândido de Figueiredo; José Leite de Vasconcelos; José Joaquim Nunes e David Lopes.

${ }^{15}$ Assinado, em Portugal, pelo presidente da ACL, Júlio Dantas bem como o embaixador brasileiro, José Bonifácio de Andrada e Silva, e, no Brasil, o presidente da ABL, Fernando Magalhães, assim como pelo embaixador português Duarte Leite.

${ }^{16}$ Cf. Presença, na ocasião, de observadores da Região Autónoma da Galiza. Aliás, a Galiza, pelas Irmandades da Fala da Galiza e Portugal expressariam, 
posteriormente, a vontade de participar na aplicação do Acordo da Ortografia Unificada. Vd. Reforma Ortográfica da Língua Portuguesa da Galiza.

${ }^{17}$ E.g. Base I <W, W>: dáblio. Então e o ‘duplo v’?

${ }^{18} 0$ desejo é antigo. Cf. ALMEIDA, António de: Dons artigos sobre o systema preferivel na Orthographia Portugueza, defendendo a opinião de que a escripta deve ser em tudo conforme á pronuncia: assignados por um conimbricense, [1789].

${ }^{19}$ Devem considerar-se diferentes momentos de literacia pueril, designadamente literacia precoce, antes do ensino- aprendizagem de competências de escrita e leitura; literacia emergente, que promove contactos básicos com letras, sons e actividades de segmentação e recombinação; e, finalmente, literacia decorrente de actividades escolares, com o desenvolvimento da literacia alfabética, uma competência abstracta e a sua influência em termos metafonológicos.

${ }^{20}$ Cf. imprecisões, na Base II, $2^{\circ}, \mathrm{b}$.

${ }^{21}$ Base IV. Cf. Anexo II.4. 0 critério, todavia, não se aplica em todas as Bases. Cf. Base I.5. ${ }^{\circ}$ : "As consoantes finais grafadas $b, c, d$, g e $t$ mantêmse, quer sejam mudas quer proferidas” (e.g. <David>).

${ }^{22}$ Colocar-se-á, eventualmente, a questão de saber quais os limites a impor ao uso, numa língua. Designadamente, com base na facultatividade admitida de formas como <enxáguas> (Base X, 7. ${ }^{\circ}$ ), criar-se-á espaço para debater a legitimidade e a pertinência do letramento, face ao mero uso. Vd. por hipótese, [<fáçamos $>$ ] [ $<$ séjamos $>]$ / [<vacina $>$ ] / [<alcoolémia $>$, ou quiçá, seguindo o critério do 'uso', [<tulipa $>$ ], por < túlipa $>$ ?

${ }^{23}$ Cf. conceito de 'falsas esdrúxulas', confundindo-se o vocábulo proparoxitono em termos gráficos e a sua verbalização corrente com duas ou três sílabas. Base XI. $3^{\circ}$.

${ }^{24}$ Entre as posições negativas, destaquem-se, do lado português. A Associação Portuguesa de Linguística, em parecer solicitado pelo Instituto Camões em 2005, concluindo: “iii) Que seja de imediato suspenso o processo em curso, até uma reavaliação, em termos de política geral, linguística, cultural e educativa, das vantagens e custos da entrada em vigor do Acordo Ortográfico de 1990." No mesmo sentido, Ministro da Cultura: Folha de São Paulo, 14/6/2008: "Se [o Acordo Ortográfico] é uma coisa boa, então que seja o mais depressa possível. Se é má, então não queremos pura e simplesmente.” Vd. também Evanildo Bechara (Lagoa, S. Miguel, Açores, 8 a 11 de Maio de 2008): “o Acordo não tem condições para servir de base a uma proposta normativa, contendo imprecisões, erros e ambiguidades”. Por outro lado, cf. 
João Malaca Casteleiro, entre outros defensores do AOLP: "As falhas que se podem apontar no Acordo Ortográfico, facilmente sanáveis, não devem impedir que a língua escrita portuguesa perca a oportunidade de se inscrever no rol daquelas que conseguiram unificação no seu sistema de grafar as palavras, numa demonstração de consciência da política do idioma e de maturidade na defesa, difusão e ilustração da língua da lusofonia.”

${ }^{25}$ Cf. OLIVEIRA, 1975 [1536], p. 52: “(...) nisto consiste o saber ler, e mais que saber ler. E é verdade que, se não tivermos certa lei no pronunciar das letras, não pode haver certeza de preceitos nem arte na língua, e cada dia acharemos nela mudança, não somente no som da melodia, mas também nos significados das vozes, porque só mudar uma letra, um acento ou som, e mudar uma de vogal grande ou pequena ou de pequena a grande, e assim também de uma consoante dobrada em singela ou, ao contrário, de singela dobrada, faz ou desfaz muito no significado da língua."

Recebido em 05 de janeiro de 2015.

Aprovado em 15 de janeiro de 2015. 